\title{
Bench-Scale Preparation and Qualitative Analysis of Calcium Chloride from Locally Available Raw Materials
}

\author{
Fauzia Sultana*, Tanjila Alam and A.K.M.A. Quader \\ Department of Chemical Engineering, Bangladesh University of Engineering and Technology (BUET) \\ Dhaka -1000, Bangladesh \\ Email: fauziasultana27@gmail.com, quader@che.buet.ac.bd
}

\begin{abstract}
Calcium chloride has diverse industrial applications. In spite of its demand and availability of raw materials locally, there are no chemical industries in Bangladesh that produce calcium chloride as a major product. This work was undertaken to assess the feasibility of production of calcium chloride on bench-scale by limestone-hydrochloric acid process and the quality of the product. Different amounts of limestone and $35.5 \%$ hydrochloric acid (by weight) were reacted in a PVC reactor to produce calcium chloride. Solubility at different temperature, $\mathrm{pH}$, and calcium content were among the parameters measured to assess the product quality. FTIR Spectroscopy was also conducted to determine the quality of the product. Solubility values of the product ranged between $96-155 \mathrm{~g} / 100 \mathrm{~g}$ water for temperatures between $30-100^{\circ} \mathrm{C}$; calcium content of the product was found to be $25 \%$.
\end{abstract}

\section{INTRODUCTION}

Calcium Chloride $\left(\mathrm{CaCl}_{2}\right)$, a white crystalline salt, is commonly used in road de-icing, medicine, food industry, as desiccant or as a calcium source [1,2]. For its high exothermicity, calcium chloride is capable of absorbing moisture, several times its own weight.

Calcium chloride is commercially available as anhydrous and dihydrate flakes, pellets and powder, or as a standard $30-45 \%$ solution. Commercial methods of production of calcium chloride include the Solvay process, where brine is reacted with limestone, and the natural brine process where calcium chloride is a byproduct [2]. In the laboratory, calcium chloride can be prepared by slaked lime-hydrochloric acid or limestone-hydrochloric acid process.

The limestone-hydrochloric acid process is best described by Eq. (1), where calcium carbonate is reacted with hydrochloric acid to give calcium chloride.

$\mathrm{CaCO}_{3}+2 \mathrm{HCl} \rightarrow \mathrm{CaCl}_{2}+\mathrm{CO}_{2}+\mathrm{H}_{2} \mathrm{O}(1)$

Because of its versatility as a compound, consumption of calcium chloride is increasing all over the world and its demand is expected to rise in the near future. Each year, Bangladesh imports approximately 355 tons of calcium chloride worth Tk $\mathbf{1 1 . 3 5}$ million for use in different sectors including medicine and health, fertilizer, paint, etc [3]. Natural calcium carbonate is available in the north eastern part of Bangladesh. Also, commercial grade hydrochloric acid is locally produced. However, in spite of its high demand and the availability of raw materials locally, no local industry produces calcium chloride.

This work was undertaken to perform limestonehydrochloric acid reaction on bench-scale to assess the feasibility of producing calcium chloride with local raw materials and to analyse the product formed.

\section{MATERIALS AND METHODS}

The raw materials used for the work were calcium carbonate and hydrochloric acid. Commercial grade calcium carbonate and $35.5 \%$ hydrochloric acid (by weight) were used. A PVC reactor (capacity 17L), fitted with a motor driven agitator was used to carry out the reaction. To concentrate the resulting solution of calcium chloride, a stainless steel jacketed evaporator (capacity 30L) fitted with a sieve filter on the top was used. The concentrated product, in ceramic bowls, was dried in an electric oven. The reaction was carried out at room temperature. A combined glass electrode was used to measure $\mathrm{pH}$ of the product. Reagent grade ammonium oxalate and standardized potassium permanganate solutions were used to perform titration of calcium chloride. FTIR Spectroscope (SHIMADZU) was used to perform a spectroscopy of the calcium chloride produced. Further details of the experimentation are provided elsewhere [7].

\subsection{Preparation of calcium chloride}

Different stoichiometric amounts of commercial grade $35.5 \%$ hydrochloric acid and calcium carbonate were added to a PVC reactor. The reaction was accelerated by agitation. After the completion of the exothermic reaction, the solution was passed through a sieve filter to remove grits and suspended particles. The clean solution thereafter was concentrated in a jacketed evaporator using steam as the heating medium. The resulting concentrated calcium chloride sludge was collected in ceramic bowls and dried at $150^{\circ} \mathrm{C}$ (appx) in an electric heater for 5-6 hours in small batches. The dry product was weighed and analysed for product purity.

\subsection{Measurement of $\mathrm{pH}$ of calcium chloride}

The $\mathrm{pH}$ of calcium chloride formed was measured as a parameter to determine product purity. The $\mathrm{pH}$ of $18 \%$ 
solution (randomly selected) was measured using a combined glass electrode, which was calibrated against distilled water.

\subsection{Measurement of Solubility of calcium chloride}

Solubility of calcium chloride formed was measured by gradually adding the salt to $100 \mathrm{ml}$ of water in a beaker placed on a hot plate stirrer. Before adding it to the water, the salt was crushed and made into fine powder. Saturation of the solution was confirmed by observing the presence of undissolved calcium chloride. Temperatures of the solution were varied between 30$100^{\circ} \mathrm{C}$ by regulating the hot plate stirrer. The solution was continuously stirred with a magnetic stirrer to ensure slow cooling and avoiding super saturation.

\subsection{Determination of calcium content of the calcium chloride}

Soluble calcium content of the product was measured by standard complexometric titration. The calcium chloride formed was solubilized in water and reacted with reagent grade ammonium oxalate $\left(\mathrm{NH}_{4}\right)_{2} \mathrm{C}_{2} \mathrm{O}_{4}$ in the presence of sulphuric acid [Ref, if possible].

$$
\begin{gathered}
\mathrm{Ca}^{2+}+2 \mathrm{HCl}(\mathrm{aq}) \rightarrow \mathrm{CaCl}_{2}(\mathrm{aq})+\mathrm{H}_{2}(2) \\
\mathrm{CaCl}_{2}+\left(\mathrm{NH}_{4}\right)_{2} \mathrm{C}_{2} \mathrm{O}_{4}(\mathrm{aq}) \rightarrow \mathrm{CaC}_{2} \mathrm{O}_{4}(\mathrm{~s})+2 \mathrm{NH}_{4} \mathrm{Cl}(3) \\
\mathrm{CaC}_{2} \mathrm{O}_{4}(\mathrm{~s})+2 \mathrm{NH}_{4} \mathrm{Cl}(\mathrm{aq})+\mathrm{H}_{2} \mathrm{SO}_{4}(\mathrm{aq}) \rightarrow \\
\mathrm{CaSO}_{4}(\mathrm{aq})+\mathrm{COOH} \cdot \mathrm{COOH}(\mathrm{aq})(4)
\end{gathered}
$$

The resulting solution containing oxalic acid was titrated against standardized $0.0102 \mathrm{~N}$ potassium permanganate solution.

\subsection{Product Spectroscopy}

A sample of the calcium chloride formed was treated with potassium bromide and placed in a SHIMADZU FTIR Spectroscope. The corresponding absorption peaks obtained for the sample were compared to those of known compounds.

\section{RESULTS AND DISCUSSION}

Assessment of the feasibility of producing calcium chloride with locally produced raw materials by performing limestone-hydrochloric acid reaction on bench-scale and analyses of the product were the main objectives of this work. Different stoichiometric amounts of limestone and commercial grade hydrochloric acid were reacted in a PVC reactor; solubility, $\mathrm{pH}$, and calcium content were among the parameters measured to determine product quality. Prolonged drying period was a major limiting factor of the work. Calcium chloride from the evaporator was in the form of sludge which when dried in the oven formed a thin white crust on the top. This made drying difficult; and the crust had to be broken time and again to initiate evaporation of water from the product. This resulted in a longer drying period.

\subsection{Calcium content and purity of calcium chloride} Standard complexometric titration with ammonium oxalate was performed to determine the calcium content of the dry product formed [2]. When calcium chloride was reacted with ammonium oxalate, calcium oxalate was formed, which was later treated with sulfuric acid. The resulting oxalic acid was titrated with standard potassium permanganate solution. The product was found to contain $25 \%$ calcium by weight.

$\% \mathrm{Ca}=\frac{\text { grams of } \mathrm{Ca}}{\text { grams of sample }} \times 100 \%$

Theoretically, the elemental calcium content of calcium chloride is around $36 \%$. This difference between theoretical and experimental values suggests the possibility of the presence of other cations in the product, besides calcium.

\section{$3.2 \mathrm{pH}$ of calcium chloride}

The $\mathrm{pH}$ of an $18 \%$ solution of the product calcium chloride was measured using combined glass electrode calibrated against distilled water, and was found to be 9. $\mathrm{pH}$ values of $20-45 \%$ calcium chloride solution range between 3.8-9 [4], hence confirming the quality of the product formed.

\subsection{Solubility of calcium chloride}

Solubility, which is a characteristic property, was analysed to determine quality of the calcium chloride formed. Solubility was measured for temperatures ranging $30-100^{\circ} \mathrm{C}$.

The comparison between literature and experimental values of solubility of calcium chloride formed is shown in Table 1. The comparison shows slight deviations between the two sets of values. A graphical representation of the comparison of solubility values is also shown in Fig. 1.

Table 1: Comparison of solubility (Literature and Experimental) of calcium chloride in water

\begin{tabular}{ccc}
\hline $\begin{array}{c}\text { Temperature } \\
\left({ }^{\circ} \mathrm{C}\right)\end{array}$ & $\begin{array}{c}\text { Experimental } \\
\text { values } \\
(\mathrm{g} / 100 \mathrm{~g} \text { water })\end{array}$ & $\begin{array}{c}\text { Literature } \\
\text { values }[5] \\
(\mathrm{g} / 100 \mathrm{~g} \text { water })\end{array}$ \\
\hline 30 & 96 & 100 \\
40 & 125 & 128 \\
60 & 140 & 137 \\
80 & 142 & 147 \\
90 & 151 & 154 \\
100 & 155 & 159 \\
\hline
\end{tabular}




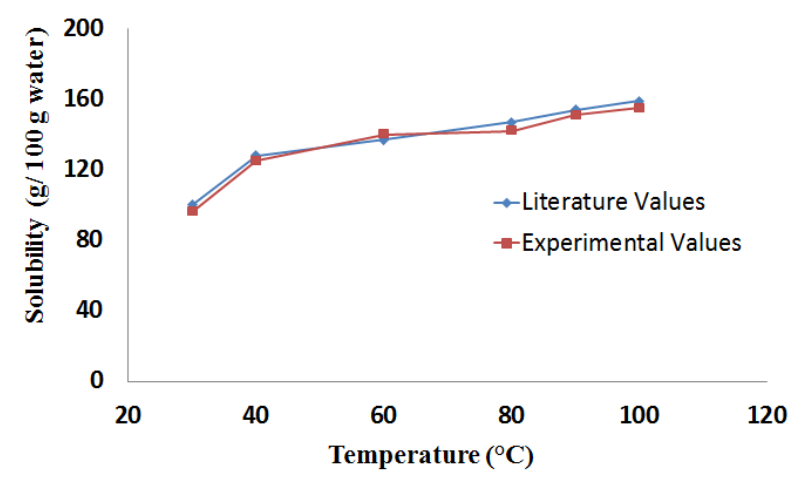

Fig. 1: Solubility of calcium chloride (Literature and Experimental values).

Solubility of a substance is sensitive to factors including temperature and pressure. Fig. 1 shows slight deviations between literature and experimental solubility values. Such deviation suggests incomplete drying of calcium chloride, unsteady temperature during solubility measurement, or the presence of impurities in the raw materials or the product.

\subsection{Product spectroscopy}

Spectroscopy is often performed for physical and analytical identification of substances, where the peaks are characteristic of the substance analysed. To further assess the quality of the calcium chloride formed, Fourier Transform Infrared (FTIR) Spectroscopy was conducted. A wide range of peaks were obtained; among these a prominent peak was observed at around $1456.2 \mathrm{~cm}^{-1}$, which is close to the characteristic peak value of calcium chloride. A wide cluster of frequency values ranging from 3300.0-3589.3 $\mathrm{cm}^{-1}$ was also observed in the spectroscopy image. Typically, resonance frequency of $-\mathrm{OH}$ in water is around 3450 $\mathrm{cm}^{-1}$ [6]. This cluster of peak values suggests the presence of free or dissolved water in the product, or the interference of $-\mathrm{OH}$ group in other species present in the product.

\section{CONCLUSION}

This work confirms the potential of producing calcium chloride using locally available limestone $\left(\mathrm{CaCO}_{3}\right)$ and hydrochloric acid on industrial scale to meet the local requirement of calcium chloride for different uses and applications. The product calcium chloride of this work is of good quality and the quality can be further improved by pretreatment and beneficiation of lime stone. Further studies are required at pilot plant level for collecting data and learning operational problems before designing a commercial plant indigenously.

\section{REFERENCES}

[1] D.E. Garrett, Handbook of Lithium and Natural Calcium Chloride, Academic Press, 2004, p. 358-376.

[2] P. Patnaik, Handbook of Inorganic Chemicals, Mc-Graw Hill, 2003, p. 158-159, 161-163.

[3] National Bureau of Revenues, Bangladesh, data acquired in 2001.

[4] Material Safety Data Sheet, Tetra Technologies, Inc, 2010.

[5] Solubility Table. Available at http://en.wikipedia.org/wiki/Solubility_table. Retrieved January 2011.

[6] Fourier Transform Infrared Spectroscopy, in Machinery Lubrication: Practicing Oil Analysis, Noria Publication, 2002.

[7] Fauzia Sultana and Tanjila Alam, 'Production of Calcium Chloride by Limsestone-Hydrochloric acid Process', B.Sc. Eng. Chemical Thesis, Bangladesh University of Engineering and Technology (BUET), Dhaka, 2011. 